\title{
(RE)SIGNIFICANDO A EDUCAÇÃO EM SAÚDE: DIFICULDADES E POSSIBILIDADES DA ESTRATÉGIA SAÚDE DA FAMÍLIA
}

\author{
RESIGNIFYING EDUCATION IN HEALTH:DIFFICULTIES AND POSSIBILITIES OF THE FAMILY HEALTH STRATEGY \\ (RE)SIGNIFICACIÓN DE LA EDUCACIÓN EN SALUD:DIFICULTADES Y POSIBILIDADES DE LA ESTRATEGIA \\ SALUD FAMILIAR
}

Silvia Regina Gomes de Oliveira ${ }^{1}$

Águeda Lenita Pereira Wendhausen ${ }^{2}$

Resumo Este estudo qualitativo objetivou conhecer a concepção e a vivência de 27 trabalhadores da Estratégia Saúde da Família sobre educação em saúde. O desenvolvimento da problematização, como pensada por Paulo Freire, facilitou o trabalho grupal participativo. Neste recorte, foram discutidas duas das categorias: práticas educativas e seus enigmas; e (re) significando as práticas educativas. Os temas trazidos foram codificados, decodificados e desvelados criticamente, bem como expressas as dificuldades, possibilidades e expectativas da ação educativa. Os resultados revelaram as dificuldades dos sujeitos em diferentes aspectos do agir educativo em suas práticas e como são fortes os resquícios de uma prática bancária, preventiva e medicalizada. A reflexão que daí procedeu sensibilizou-os, o que demonstrou potencial para o desenvolvimento de práticas educativas transformadoras e a necessidade de uma educação permanente, a fim de ampliar suas habilidades dialógicas.

Palavras-chave promoção da saúde; saúde da família; educação em saúde.
Abstract This qualitative study aimed to get to know the conception and experience of 27 Family Health Strategy workers on health education. The development of problematizing, as thought by Paulo Freire, facilitated participatory group work. Two of the categories were discussed in this survey: Educational practices and their enigmas; and (re)signifying educational practices. The subjects that were brought up were encoded, decoded and critically unveiled, and the difficulties, possibilities and expectations of the educational action expressed. The results revealed the subjects' difficulties in different aspects of the educational act in their practices and how strong the remnants of a bank, preventive, and medicalized practice are. The reflection coming from this touched them, showing potential for the development of transformative educational practices and the need for continuing education in order to expand their dialogical skills.

Keywords promotion of health; family health; health education. 


\section{Introdução}

Até a década de 1970, a educação em saúde oficial restringia-se a questões higiênicas e sanitárias, de caráter individualista, autoritário e assistencialista, e estava ligada diretamente aos interesses de uma elite política e econômica que estabelecia normas e condutas (Vasconcelos, 2006). Essa situação gerou insatisfação e descontentamento na população, levando à formação, no final da década de 1950 e início da década de 1960, de alguns movimentos sociais de populares e intelectuais.

A concepção de saúde e da educação em saúde entrou em pauta nos debates nacionais e internacionais, como nas conferências de Alma-Ata (1978) e de Ottawa (1986), que enfatizavam a assistência primária e a promoção da saúde. A partir do movimento da Reforma Sanitária nos anos 1980, as práticas educativas passaram a priorizar o processo dialógico com a população para resolverem seus problemas. A educação em saúde adquire, então, novas feições, e a população e os profissionais da área da saúde podem compartilhar saberes, buscando, conjuntamente, a melhoria da qualidade de vida das pessoas. Com isso, a educação em saúde passa a ser um instrumento para promover a saúde de um modo participativo, dialógico e emancipatório, valorizando-se a autonomia da população e sua corresponsabilidade no processo saúde-doença (Wendhausen e Saupe, 2003). No entanto, mesmo havendo adesão por parte de alguns profissionais da saúde a esse enfoque, observa-se, na prática, que a educação em saúde se manteve tão prescritiva e autoritária quanto antes da Reforma Sanitária.

O Sistema Único de Saúde (SUS), ancorado em seus princípios e diretrizes, vem sofrendo diversas alterações relativas à operacionalização de suas ações. Dentre elas, foi implantada a Estratégia Saúde da Família (ESF), que permite aos trabalhadores desenvolverem uma prática assistencial humanizada, dinâmica, renovadora e integral, prática que passou a reorientar a assistência, que teve sua atenção voltada para a família inserida em uma comunidade.

O Programa Saúde da Família (PSF), instituído em 1994, posteriormente denominado Estratégia Saúde da Família, propôs-se a ampliar a cobertura dos serviços de saúde, rediscutindo as ações educativas numa perspectiva dialógica, emancipadora e participativa. Como ressaltam Chiesa e Veríssimo (2001), foi preciso estruturá-la mediante o fortalecimento da atenção à saúde e a ênfase na integralidade da assistência, no tratamento do indivíduo (como sujeito integrado à família, ao domicílio e à comunidade), no aumento da capacidade resolutiva da rede básica de atenção, na vinculação dos profissionais e serviços à comunidade e na perspectiva de promover uma ação intersetorial. Nessa proposta, a educação em saúde destaca-se como ferramenta de trabalho, auxiliando o trabalhador da saúde e a comunidade a 
refletirem sobre si mesmos, sobre a realidade e sobre as ações para uma vida mais saudável (Brasil, 2004).

Nesse novo contexto, destacam-se experiências positivas, com profissionais comprometidos em atuações que emergem da realidade na qual estão inseridos atores sociais que interagem na busca dos enfrentamentos dos problemas de saúde e da integração dos saberes técnico e popular (Vasconcelos, 2006). Todos os trabalhadores da área da saúde são responsáveis por atuar nessa prática. A tarefa é de toda a equipe na unidade de saúde, embora a equipe nem sempre esteja preparada para exercê-la. Essa é uma problemática com a qual nos deparamos. O desenvolvimento das atividades educativas, sofrendo resquícios da transmissibilidade, reflete-se ainda em nós, que nos consideramos 'donos do saber' que repassamos a pessoas leigas e ignorantes.

A escolha do tema justificou-se por acreditarmos que a educação em saúde é muito importante no sentido de validar uma prática que comprovadamente modifica a assistência, e que, quando devidamente aplicada, impacta e transforma. O estudo se justifica também pela sua importância para os trabalhadores da ESF, uma vez que a educação em saúde é considerada ferramenta essencial na construção de uma assistência integral, contribuindo para a efetiva consolidação do modelo de assistência vigente. Enfim, por acreditarmos que possa tornar-se um instrumento de empoderamento para o indivíduo/a comunidade, quando pensado numa abordagem dialógica, emancipadora e participativa, visando à promoção da cidadania e da qualidade de vida.

Este estudo objetivou conhecer a concepção dos trabalhadores da ESF em relação ao modelo de educação em saúde e suas práticas, levando a um processo de reflexão e discussão, por meio da utilização do método Paulo Freire, porquanto ele se propõe a tornar o educando sujeito de seu trabalho. Em 2007, o Ministério da Saúde adotou metodologias ativas de aprendizagem, dentre elas a de Freire, como escolha para uma educação em saúde emancipatória. Finalmente, as pesquisadoras, ao experimentarem o método em sua própria vivência, por intermédio de um processo de pesquisa, poderão aplicá-lo mais facilmente ao usuário em seu cotidiano.

\section{Metodologia}

O estudo original (Oliveira, 2011), do tipo qualitativo, favoreceu a interação com atores sociais (Ludke e André, 1986) e buscava a sua participação na análise da própria realidade (Brandão, 2005). A pesquisa foi realizada no período de março a junho de 2010, com três equipes de ESF de um município do litoral paranaense - totalizando 27 trabalhadores de saúde -, cada 
uma delas composta de um médico, um enfermeiro, um técnico de enfermagem e seis agentes comunitários de saúde (ACSs). As ideias de Paulo Freire (Brandão, 2005) foram utilizadas na coleta de dados e dialogicamente, no grupo pesquisado, proporcionando discussões e reflexões sobre suas práticas educativas. Para Miranda e Barroso (2004), o diálogo em Freire é um encontro entre os homens mediatizados pelo mundo.

Neste estudo foram realizados quatro encontros, quando aconteceram as atividades educativas desenvolvidas mediante técnicas de oficina. Para a análise de dados, também se utilizou o referencial proposto por Freire, ou seja, baseando-se no tema educação em saúde, quais os temas geradores, como o grupo o codificava e decodificava o tema, e como, a partir daí, o desvelava e propunha ações de transformação em sua realidade.

No primeiro encontro com os trabalhadores da ESF, explicamos o que era a investigação sobre o tema educação em saúde e como se pretendia fazê-la; essa etapa foi pensada para começar a descobrir a realidade do grupo, captar a visão dos participantes sobre o assunto a ser problematizado e como lidavam com ele em seu cotidiano. Embora tivéssemos a ideia de já definir os temas geradores, não foi possível estabelecê-los nessa primeira oficina, pois, em seus depoimentos sucintos, os trabalhadores pareciam ter dificuldade de colocar as reais práticas de educação em saúde em seu cotidiano.

Na segunda oficina, propiciamos ao grupo uma interação com a realidade, e os participantes codificaram suas práticas educativas por meio da dramatização. Só então começamos, lentamente, a desvelar o entendimento e o significado que os trabalhadores da ESF tinham sobre suas atividades educativas, pois, ao dramatizarem, reportavam-se às suas ações, tal como as vivenciavam. Nesse momento, emergiram o que Freire (2005) chama de temas geradores.

Diante das questões colocadas pelos trabalhadores, optamos, na terceira oficina, por ler um texto organizado por Ceccim (2007) e refletir sobre ele. O texto reproduz um diálogo acontecido numa roda de conversa entre Paulo Freire e moradores da Vila Prudente, São Paulo, que, direta ou indiretamente, estavam envolvidos com o trabalho de educação popular, cujo assunto versava sobre os movimentos e as práticas de educação popular, destacando os cinco princípios que Freire (2005) considera fundamentais para os educadores e os trabalhadores da saúde no seu contato com a população Ceccim (2007). A terceira oficina foi o momento em que os participantes problematizaram a educação em saúde que praticavam para reconstruí-la. Freire (2005) considera essa a segunda etapa de seu método, o momento de realizar as codificações e decodificações, e de contextualizar os temas levantados, substituindo-os por uma visão mais crítica e social.

Na quarta oficina, além das decodificações, ocorreram também desvelamentos críticos, ou seja, o contato com a realidade de cada um e com o que 
precisava ser transformado - essa é a terceira etapa do método Paulo Freire. Um fator positivo do método foi a discussão com base na realidade. Observamos que discutir situações e problemas reais do cotidiano motivou os participantes a refletirem e a se questionarem sobre suas práticas.

Para preservar a identidade dos trabalhadores, seguimos, nesta investigação, as normas e diretrizes asseguradas na resolução n. 196/1996 do Conselho Nacional de Saúde (CNS), que regulamenta as pesquisas que envolvem seres humanos, dando-lhes nomes fictícios. Este estudo (Oliveira, 2011) foi submetido à Comissão de Ética em Pesquisa da Universidade do Vale do Itajaí (Univali), tendo recebido parecer favorável para o seu desenvolvimento.

\section{Resultados e discussões}

Originalmente, foram construídas quatro categorias (Oliveira, 2011) com base na reflexão sobre os dados. Neste escrito, expomos dois desses temas: "As práticas educativas e seus enigmas" e "( $\mathrm{Re})$ significando as práticas educativas". As duas categorias desse recorte refletem questões que estiveram presentes nos discursos dos trabalhadores durante as oficinas.

\section{As práticas educativas e os seus enigmas}

Dentre os temas abordados nas oficinas, sobressaíram alguns que, segundo os participantes, interferem no processo educativo, dificultando a execução da educação em saúde no município estudado. As dificuldades percebidas pelos trabalhadores da ESF quanto às práticas educativas foram classificadas pelas pesquisadoras como "As práticas educativas e seus enigmas" e aparecem de diversas formas. Em relação à educação em saúde, o despreparo dos trabalhadores foi uma delas, conforme expressada na fala a seguir:

(...) o que a educação em saúde exige é uma preparação para o trabalho. A gente tem que aprender primeiro a desenvolver o trabalho para depois executá-lo. E isso inclui (...) todos nós que atuamos (Marcos).

No entender dos trabalhadores, a formação acadêmica que receberam é insuficiente para trabalhar com a comunidade. Essa é uma realidade enfrentada por muitos trabalhadores que atuam na ESF, realidade que, sem dúvida, é um obstáculo a ser superado. O descompasso na educação em saúde, que resulta no despreparo dos trabalhadores que a realizam, possivelmente é decorrente das experiências e do conhecimento que compõem o aporte teórico desses profissionais em sua formação, aliados ao desestímulo em 
adotar a educação em saúde como estratégia para a promoção da saúde na prática profissional.

Advindo de práticas anteriores, no começo do século XX consolidou-se o paradigma da medicina científica que orientou o desenvolvimento do ensino e das práticas profissionais em toda a área da saúde. A segmentação em disciplinas, característica ainda hoje tão marcante da educação superior, tem origens no Relatório Flexner, publicado em 1910, e que mais adiante, no pós-guerra, transforma-se no modelo da 'história natural da doença' (Santana, Campos e Sena, 2004).

O modelo de educação em saúde ainda em prática em instituições de ensino superior do país reforça o perfil do profissional formado em especialidades, em detrimento da maioria das necessidades da população. Desse modo, hoje as diversas formações de trabalhadores em saúde pecam no sentido de formar um trabalhador de saúde inapto, com perfil inadequado para trabalhar as questões trazidas no e pelo SUS. Para alguns participantes, a constatação da falta de 'educação continuada' no dia a dia é um fator dificultador das práticas educativas, como podemos observar nos depoimentos a seguir:

(...) a gente precisa aprender como fazer práticas educativas continuamente. E isto inclui a mim, você, cada um de nós que trabalha com a saúde. (Edna)

A gente se acomoda (...), fica meio atrofiado (...). Quando vemos, só estamos repetindo a mesma coisa. (Adolfo)

Como é possível observar, a 'educação continuada' prevaleceu nas falas dos participantes. Em nenhum momento, o termo 'permanente' destacou-se nas discussões, provavelmente por causa do modelo tradicional que domina a assistência prestada. Para esclarecer esses conceitos, retomamos a historicidade do SUS: o modelo da educação continuada, caracterizado pela atualização de conhecimentos específicos em capacitações pontuais para determinadas categorias profissionais, seguia um padrão que não respondia aos princípios do SUS. Foi preciso encontrar uma alternativa capaz de responder ao esgotamento desse modelo. Nesse sentido, o Ministério da Saúde (MS), por meio do Departamento de Gestão da Educação na Saúde (Deges), propôs a educação permanente dos trabalhadores de saúde como estratégia para a formação dos profissionais, a transformação de suas práticas e, consequentemente, para o fortalecimento do SUS (Brasil, 2004).

A educação permanente possibilita o aperfeiçoamento daqueles que já trabalham na saúde, que adquirem conhecimentos, e o desenvolvimento das instituições, reestruturando as ações. A educação permanente tem como base a integração entre ensino e trabalho (Brasil, 2004). Expondo a Política 
Nacional de Educação Permanente em Saúde, Roschke (2008?), consultora do Departamento de Gestão da Educação na Saúde vinculado ao Deges, referindo-se à portaria do Ministério da Saúde GM/MS n. 1.996/2007, diz que a mesma reafirma os princípios da educação permanente na área como norteadores da construção dos planos regionais de educação permanente em saúde e das ações educativas na área. Diz, também, que a formação dos trabalhadores do SUS não mais será definida com base em suas necessidades individuais de atualização, e sim pautando-se nos problemas cotidianos de atenção à saúde e de organização do trabalho. As atividades de educação em saúde passam a compor o Pacto pela Saúde (Roschke, 2008?), que responsabiliza a gestão do SUS pelas ações de educação na saúde como atividade que pode e deve contribuir para o desenvolvimento do órgão, para a qualificação profissional dos trabalhadores da área e para a mudança das práticas de saúde, visando atender os princípios fundamentais do SUS.

A educação permanente leva à construção de um novo conhecimento e ao fortalecimento do usuário/grupo/comunidade, pela problematização da realidade vivenciada e pelo desenvolvimento da capacidade de aprender a criticar, a fim de que sejam construídas, reflexivamente, novas práticas de educação em saúde, com possíveis soluções dos problemas. A prática crítica envolve o movimento dinâmico, dialético, entre o fazer e o pensar sobre fazer. É por isso que, na formação permanente, o momento fundamental é o da reflexão crítica sobre a prática (Freire, 2005): é pensando criticamente a prática de hoje ou de ontem que se pode melhorar a próxima prática.

Outro aspecto que dificulta o processo educativo surgiu na terceira oficina, quando os participantes codificaram a falta de estrutura física das unidades, e até mesmo a falta de tempo para conversarem e trocarem experiências através do diálogo.

No momento, isso seria inviável devido às condições inadequadas do local: nós não temos onde colocar todo esse povo [ usuários da unidade] (Elaine).

Com as condições que temos, é muito difícil realizar qualquer coisa desse tipo [ação educativa] (Aparecida).

Na nossa unidade, as orientações também são realizadas basicamente pelos ACSs nas visitas domiciliares e sempre individualmente, quando muito para a família (Estér).

Essa falta de estrutura é verdadeira, mas também pode ser pensada por outro ângulo, dentro do contexto da realidade na qual estamos trabalhando. Ou seja, as atividades educativas devem estar ligadas às prioridades discutidas pelos profissionais e a população, e devem estar vinculadas às outras 
atividades da equipe, de modo a não transformar a educação em saúde em mais uma 'coisa a fazer' (Dierks e Pekelman, 2007).

Também constatamos no discurso de alguns participantes que eles não se percebem como mediadores do processo de participação da comunidade. O trabalhador de saúde precisa ter clareza do seu papel como sujeito do processo educativo e compreender que uma ação educativa não precisa necessariamente acontecer no espaço de uma unidade de saúde. Espaços criados pela comunidade, como eventos esportivos, recreativos e até mesmos sociais, são momentos importantes para a mobilização da população. É preciso, contudo, ter o cuidado de não utilizá-los de maneira normalizadora, com atividades predeterminadas, para não desperdiçar a chance de interagir com a comunidade. Nesse caso, o que vale é a mudança de postura do trabalhador em saúde, pois, a partir do momento em que o trabalhador (re) signifique as suas práticas educativas, ele assumirá o papel de mediador.

Existe uma ação educativa não intencional em todas as ações dos trabalhadores de saúde (Briceño-Leon, 1996). Esse modo informal de educar representa uma possibilidade de comunicar as mais diversas mensagens, nas mais variadas situações. A dimensão educativa das ações dos trabalhadores torna a postura um fator importante quando se considera a participação em saúde. O trabalhador de saúde deve estar apto a desenvolver a função de mediador (Freire, 2007), entendendo que é o usuário quem, em última instância, decide sobre a própria saúde, devendo o profissional informar-lhe, dialogar com ele e apoiar a sua atitude. O trabalhador de saúde deve se interessar pela vida e pelo meio no qual as pessoas vivem, e, com base nisso, desenvolver uma relação dialógica. Ao adotar uma postura dialógica, o trabalhador e a comunidade se beneficiam do intercâmbio, atuando como parceiros na busca por melhorias e qualidade de vida.

Outro aspecto referenciado por vários trabalhadores diz respeito ao fato de a população relutar em aceitar uma nova perspectiva de atendimento, uma vez que, entre as atividades executadas pela equipe em uma unidade de ESF, os usuários privilegiam as consultas médicas. Isso pode ser resultado da intensa medicalização à que todos fomos submetidos, profissionais e usuários dos serviços de saúde, principalmente no século passado. O processo de medicalização social pode ser visto, muito sinteticamente, como a expansão progressiva do campo de intervenção da biomedicina por meio da redefinição de experiências e comportamentos humanos como se fossem problemas médicos (Tesser, 2006). Um dos elementos mais importantes na transformação da vida em algo medicalizável é a associação conceitual entre saúde/normalidade e doença-patologia/anormalidade. Com base nessa percepção, justifica-se a normalização da vida, para que ela se prolongue ao máximo e que seja produtiva ao máximo, e o médico passa a ser aquele que 
está autorizado (socialmente) a dizer a 'verdade da doença' ao doente (Wendhausen, 2002). Alguns depoimentos denunciam esse fato:

As pessoas não querem, muitas vezes, conversar. Elas querem consultar. Para elas, só a palavra do médico vale! (Aurora).

O que eles querem é pegar receita, é fazer consulta. Tem médico? É só isso que eles perguntam (Edna).

(...) lá na nossa unidade também é assim. O paciente sai satisfeito quando passa pelo médico e com um monte de remédio nas mãos (Terezinha).

É evidente que o perfil delineado por essas falas nos remete ao modelo tradicional, biomédico de saúde, no qual o indivíduo está muito preocupado em obter a cura, colocando o médico como o seu salvador. O seu entendimento de saúde se restringe somente à doença e na à prescrição de exames e medicamentos. Esse modelo ainda parece permear, de maneira bastante efetiva, as concepções e, consequentemente, as práticas da assistência e as ações educativas na saúde. A medicalização reforça a ideia de saúde com maior quantidade de medicamentos, consultas e exames, em detrimento dos problemas de saúde da população relacionados às suas situações de vida (Vasconcelos, 2006). Desse modo, a aspiração da população, voltada para a procura desses serviços, permanece arraigada à cultura da comunidade e também aos próprios trabalhadores de saúde, que não prezam pela participação na vida da comunidade, desestimulando ações de cidadania e mais autônomas.

Na integração do serviço de saúde com a comunidade em que o mesmo está inserido, é relevante que atores diversificados se encontrem para refletir sobre suas práticas e se fortalecer. E, fortalecidos, podem praticar uma educação em saúde crítica, com vínculos entre os trabalhadores e indivíduos, grupos e comunidades, que podem participar do sistema, bem como das decisões referentes à sua vida (Kleba, 2004).

Conhecer a necessidade e/ou a realidade de cada um e a própria comunidade, conhecer os seus problemas, nos levará a atuar continuamente; mas, para isso, é preciso que sempre estejamos abertos para adquirir conhecimentos (Marcos).

(...) não estamos acostumados a expor nossos desejos e conhecimentos. Por isso, eu concordo com o Marcos, e acho ainda que continuamente, nós, trabalhadores, deveríamos nos reunir para esse tipo de discussões (Elaine). 
A crença na possibilidade de mudanças ainda é muito tênue, pois tanto os obstáculos da realidade profissional quanto o não envolvimento da gestão local e a inexistência de uma proposta de educação permanente para o município em que atuam inviabilizam esse processo de aprendizagem, afastando-os do novo modelo de saúde proposto pelo SUS. É relevante que haja uma aderência à educação permanente, no município estudado, por todos os envolvidos nos serviços de saúde, inclusive pelo gestor. A sensibilização dos gestores é fundamental em qualquer tipo de mudança. Pouco adiantará o investimento em recursos humanos do serviço se ordenadores, administradores e políticos não tiverem compromisso com os princípios do SUS e com a inversão do modelo de assistência (Cutolo, 2003). A distância entre gestor e trabalhador pode levar ao desestímulo, conforme expressado:

(...) não adianta a equipe local se unir se não tem adesão do geral, da secretaria. O diálogo é vertical, e cumpra-se. É um desafio trabalhar em equipe; é muito desestimulante você querer fazer algo e ser barrado por sua chefia (Marcos).

Não podemos negar que a educação busca sempre a transformação. Porém, o primeiro passo para provocar a mudança no processo de formação é entender que as propostas não podem mais ser construídas isoladamente, e nem de cima para baixo. Por sua vez, adquirir conhecimento favorece o empoderamento, na medida em que possibilita a tomada de decisões conscientes dos indivíduos e da comunidade.

Outro aspecto observado em relação às dificuldades na realização das práticas educativas diz respeito ao entendimento de alguns participantes sobre a educação em saúde.

São bases [educação e saúde] para uma vida saudável: uma depende da outra. A saúde pode ser o resultado de uma boa educação. Sem o esclarecimento da sua doença, fica mais difícil de ser tratado e levar à cura (Aldo).

Pela educação é que começamos as ações em saúde. É ela que promove o conhecimento científico e também é através da educação que conseguimos passar o conhecimento para que a pessoa cuide da sua saúde (Antônio).

Para esses trabalhadores, ter saúde significa 'ter estudo'. Se a pessoa for culta, tem melhores condições de saúde e qualidade de vida - o que em parte é verdade, pois realmente o nível de escolaridade pode interferir positivamente na saúde, mas não é o único determinante. Eles a compreendem principalmente como uma educação formal, esquecendo ou até desconhecendo que a comunidade possui um saber próprio que deve ser valorizado na interação trabalhador/comunidade. 
Eles não sabem a parte técnica, mas têm muita sabedoria. (Agnes)

Para ser um educador em saúde, não é preciso especializar-se em educação, mas se compreender como sujeito/trabalhador ativo do processo da realidade e gerador das mudanças necessárias, rompendo com a herança de uma prática muitas vezes subordinada aos interesses das instituições ou, até mesmo, a outras práticas profissionais (Chiesa, Bertolozzi e Fonseca, 2000). Essa nova proposta de relações educativas exige a formação de um trabalhador crítico, com um campo de visão ampliado para enfocar os problemas em profundidade. Em contrapartida, as escolas de formação em saúde continuam gerando grandes mananciais de especialistas. Consequentemente, na realidade da saúde pública de nosso país, a educação em saúde não é abordada conforme os princípios que regem o SUS.

\section{(Re) significando as práticas educativas}

Nesse tema discorremos sobre o processo reflexivo acontecido nas oficinas, em conjunto com os participantes que decodificaram ou desvelaram criticamente alguns aspectos do agir educativo de suas práticas. Podemos considerar esse momento como a terceira etapa do método adotado; embora não aconteça isoladamente, o desvelamento crítico resulta da análise e consequente reconstituição de situações vivenciadas através da reflexão (Freire, 2007).

Para auxiliar no processo, como já dissemos, os participantes tiveram acesso a um texto que reproduzia uma roda de conversa cuja temática se centrava nos movimentos e nas práticas de educação popular (Ceccim, 2007). A reflexão que daí procedeu sensibilizou os participantes, que até então tinham, em suas ações, aspirações a serem os donos do saber:

Na verdade a gente se acha o todo-poderoso (Arnaldo).

(...) Por saber, por estar lá para passar [a informação], temos que conversar mais, dar espaço para a pessoa expor o que acha (Marcos).

Talvez isso ocorra pelo fato de o trabalhador de saúde reiterar a supremacia do saber científico em detrimento do saber popular. A historicidade da educação em saúde no Brasil nos revela que a valorização do saber científico contribui para uma atenção direcionada às demandas dos serviços em lugar das necessidades dos usuários (Vasconcelos, 2006). Para Leonello e Oliveira (2009), a hierarquização entre esses dois saberes desenvolve no trabalhador de saúde uma postura onipotente, pela qual ele se julga detentor de um saber legitimado. Consequentemente, o trabalhador de saúde não se 
compromete com o usuário. Para Freire (2007), essa distância aliena o trabalhador de sua realidade.

Por outra parte, a realidade vivenciada por trabalhadores da ESF contribuiu para momentos de importantes desvelamentos, que nos permitiram vislumbrar a tênue luz de mudança, conforme ilustrado nas falas que seguem:

Tinha outra ideia do que seria uma roda de conversa. Eu pensava que a gente fosse com um assunto certo, e ali se promoveria a discussão. E agora estou tendo outra noção. Achei uma coisa nova, e vai ter um resultado melhor [o trabalho] se eu souber sobre o que a comunidade quer conversar e não levar um assunto que talvez não seja do interesse deles. Seria uma proposta com mais diálogo (Amábile).

(...) no nosso caso, como ACSs, nós tivemos um curso de seis meses; nós aprendemos o que tínhamos que falar lá, e o que a gente ia falar é o que ia valer. Aí você [aponta para a facilitadora] vem e em poucas horas dá um nó na cabeça (...). Nos fez perceber o nosso erro, nem sei se pode dizer erro, mas nós só chegávamos lá e (...) só despejávamos. Agora não, agora a gente está aprendendo que tem de ouvir também (Adolfo).

Nós fizemos o curso, nós somos formadores - ficou tão incutido isso na nossa cabeça, que somos formadores de opiniões, e de repente a gente vê (...) que não pode fazer por ele, e sim com ele. É difícil até para nós, chegar assim e mudar: temos que aprender mais, agora temos que especular mais (Amanda).

Leonello e Oliveira (2009) esclarecem que não se trata de valorizar o saber popular, mesmo porque ele está cheio de contradições, incertezas e preconceitos, nem tampouco o saber científico, com as suas 'certezas científicas indiscutíveis', e sim compreender que o respeito ao saber popular e o reconhecimento da incompletude do saber científico é relevante para o desenvolvimento da educação em saúde pautada no SUS.

De conformidade com Wendhausen e Saupe (2003), pensamos que a visão imediatista precisa ser revista para que o trabalhador compreenda as peculiaridades de uma ação educativa que impacta o sujeito e o transforma. E reconhecer a necessidade de rever nossa postura educativa é o primeiro passo nesse processo de transformação. Nessa altura, os trabalhadores perceberam que possuem a importante tarefa de compartilhar seus conhecimentos. Porém, várias são as dificuldades no exercício dessa prática. Veja a seguir:

O engraçado disso tudo é que a gente reclama que a comunidade tem dificuldade em aceitar mudanças, mas nós também somos assim. Vejam hoje, a gente está aqui aprendendo uma nova maneira de trabalhar em nosso dia a dia, certo? E o que 
estamos fazendo? Alguns relutam, ou talvez não estejam relutando: estejam pensando, refletindo e conversando bastante. E quando começarmos a agir dessa maneira, lá com a comunidade, a gente vai ter uma resposta que vai ser uma solução deles. Eles vão começar a refletir. Então vamos tornar este estudo um momento para que a gente possa refletir e tentar fazer isso na comunidade, para ver se a resposta vai ser melhor dessa maneira ou da outra, dando uma ordem, impondo (Amábile).

Uma das dificuldades consiste em aprender a superar as concepções tradicionais em suas práticas a constituir uma cultura crítica entre si e a comunidade com a qual trabalham. Essa superação ocorrerá quando o trabalhador assuma uma postura de parceria no processo de aprendizagem, trabalhando com indivíduos a quem considera sujeitos de suas vidas. O trabalhador precisa colocar-se na posição daquele que comunica um saber relativo a outros que também possuem um saber relativo. Deve ter humildade e ser crítico, não se apresentando como único agente de mudança, pois entende a transformação social como uma tarefa que compete a todos os envolvidos e comprometidos com a mesma (Freire, 2005). Além disso, a mudança é um salto de qualidade, possível na prática, por meio de estratégias que incluam a reavaliação contínua, embora seja um processo moroso, devido às nossas limitações humanas.

A prática educativa pode ser participada, na medida em que seja reavaliada cotidianamente, em parceria com os usuários no processo de ação-reflexão-ação, sendo necessário compreender as práticas educativas como parte da educação em saúde, práticas que se constroem e se fortalecem na convivência diária com o usuário, favorecendo o exercício da cidadania (Wendhausen e Saupe, 2003). Por meio dos diálogos que tiveram lugar nas oficinas, observaram-se possibilidades de transformação.

Mudamos para aprimorar mais o aprendizado, as ações que viermos a fazer em relação à comunidade. É com os erros que nos aprimoramos (Estér).

Como aplicar nossa aprendizagem ao nosso dia a dia? (Terezinha).

Saber ouvir e falar o que acontece com as pessoas. Questionar as informações para que a pessoa pense no que está acontecendo (Marcos).

Eu me sinto mais capaz para dialogar com a população da forma certa, pois a gente está aprendendo fazendo, espero ensinar fazendo também (...) (Antônio).

(...) nós temos que aprender a estar com o outro mesmo. E treinar bastante para isso, porque essa visão equivocada das pessoas, e até nossa mesmo, de trabalhar para a comunidade fica resumida a ações individuais e até sem muito resultado positivo (Edna). 
Na interpretação dos discursos dos participantes, refletidos nas ações educativas, percebe-se que, apesar das dificuldades, existe a preocupação em construir essa nova prática. Esses trabalhadores tentam compreender os seus papéis, visando à promoção da saúde. Desse modo, o trabalhador deve entender que, servindo de elo para a operacionalização dos princípios e diretrizes do SUS, agindo como mediador do processo educativo, viabiliza a construção de sujeitos mais fortalecidos. Para que isso aconteça, entretanto, devemos nos despir de comportamentos indutivos e opressores:

A gente tem que se despir do que a gente sabe, diz o texto. Então, você vai ter que começar a trabalhar a partir do que a comunidade sabe (Elaine).

E atentar para as reais necessidades dos sujeitos envolvidos (usuários e a própria equipe de saúde).

Nessa interação, a problematização é um elemento importante no processo educativo do qual o diálogo é o ponto-chave. Entender como as pessoas se comportam em situações de saúde-doença e estimulá-las para a mudança sempre que necessário, valorizando seus conhecimentos, vivências e valores.

A esse respeito, podemos dizer que o enfoque educativo é um dos elementos fundamentais na nova prática educativa que traz no bojo de suas discussões a defesa da metodologia freiriana, em que o trabalhador não se coloca como detentor do saber, e sim como sujeito do processo de transformação e intervenção da realidade por meio de ações críticas e reflexivas. Um aspecto importante a considerar é o fato da ação educativa não implicar somente a transformação de um saber, mas também a transformação dos sujeitos envolvidos. Para tanto, é preciso que o discurso seja coerente com a prática (Alvim e Ferreira, 2007).

Nesse caso, a abordagem crítico-reflexiva decorrente do confronto favorece a troca de ideias e experiências entre trabalhador e usuário. É um excelente começo para estabelecer essa nova forma de se comunicar sem opressão e induções (Wendhausen e Saupe, 2003). Quando consideramos o conhecimento e as experiências da comunidade, isso permite a troca, estimulando o indivíduo ao empoderamento, e fortalece a sua autonomia e autoestima, e, consequentemente, o exercício da cidadania.

Todo aprendizado deve estar associado à tomada de consciência de uma situação real e ser vivido pelo educando (Freire, 2007). A partir do momento em que o trabalhador apoia o indivíduo inserido em uma comunidade para que tome suas próprias decisões de forma reflexiva está promovendo uma consciência mais crítica e aumentando a capacidade desse indivíduo de intervir em sua própria realidade, tornando-o um cidadão participativo. 
Enquanto sujeito partícipe de seu cuidado, o usuário reflete, questiona, recusa e aceita. Ativamente, a sua posição transforma a relação estabelecida no processo de cuidar-educar. Pode-se dizer que, sem uma ação coletiva dialogada e compartilhada com o saber popular, o conhecimento científico seguirá anacrônico, desvinculado do mundo prático (Leonello e Oliveira, 2009).

Nesse sentido, foi interessante visualizar como pequenos nós se desataram e tímidos avanços ocorreram no retorno da avaliação realizada na quarta oficina. A reflexão sobre concepções e práticas educativas resultou na reconstrução de alguns conceitos produzidos pelas equipes de trabalho, que foram nomeadas Alfa, Beta e Celta:

Pela educação é que começamos as ações em saúde. É ela que promove o conhecimento científico e também o conhecimento popular que, quando unidos na educação em saúde, conscientizam a população da importância de atitude de melhor viver, de direitos e deveres para um melhor bem-estar de todos, pela autonomia e pela liberdade (Equipe Alfa).

A educação em saúde é dever do Estado e direito de todo cidadão. É elemento fundamental na cultura de um povo ou de um indivíduo. Ela propicia o conhecimento do que é essencial à saúde e ao bem-estar de um povo. O ideal seria o comprometimento integral entre a equipe promotora de saúde e o indivíduo, num vínculo afetivo (Equipe Beta).

A educação em saúde é essencial para a vida de todas as pessoas. Há necessidade de adaptação através das orientações da equipe de ESF, focando-se desde a cultura local e conscientizando a população sobre a promoção em geral, desde a saúde ambiental, psicológica, moral, física, familiar e social. É necessária a dedicação, o compromisso da equipe com a humanização, o amor ao próximo sem distinções e sem preconceito com os valores culturais... Assim, [a educação em saúde] engloba a promoção da saúde integralmente (Equipe Celta).

Os participantes compreenderam que, para concretizar essa superação, era preciso que se portassem como mediadores, incorporando essas reflexões no seu dia a dia, como um pano de fundo balizando as suas ações.

Enfim, o trabalhador que opta por mudanças não teme a liberdade, não prescreve, não manipula, não foge da comunicação; ao contrário, procura a liberdade e a vive (Freire, 2007), considerando o ato de desvelar a realidade de significativa importância, mesmo que não implique aderir imediatamente à ação transformadora, mas encontrar em cada realidade histórica os caminhos de ida e vinda entre os desvelamentos da realidade e a sua prática, rumo à transformação. 


\section{Considerações finais}

Proporcionamos, conforme objetivou a investigação, um espaço para compartilhar saberes e experiências, de promover a valorização de potencialidades individuais e coletivas entre os participantes. $\mathrm{O}$ fator positivo no método aplicado foi a discussão com base na realidade de cada equipe. Com as encenações, o grupo revelou aspectos do seu dia a dia de trabalho, como cada um deles lida com determinado problema, e qual a visão que possuem sobre si mesmos como trabalhadores de saúde. Isto foi importante, pois discutir problemas e situações reais incentivou-os a refletir sobre as suas práticas e a decodificá-las.

A realidade indica a necessidade da reorganização do modelo assistencial e educativo no município estudado. As equipes da ESF precisam romper com essa característica de atendimento verticalizada e se convencer de que a nova proposta da educação em saúde de nascer e nutrir-se do diálogo entre educadores e educandos demanda um discurso e uma prática transformadora, mediada pela participação do sujeito em todo o processo educativo. Porém, para a sua concretude, precisamos reconhecer sua importância, abandonar estratégias de repasses de informações e adotar uma comunicação mais dialogada. São propostas inseridas no discurso emergente do modelo dialógico da educação em saúde, considerada enquanto prática social que extrapola as atividades preventivas e se insere no campo da promoção da saúde, que permeia todas as ações da equipe de saúde, ao mesmo tempo em que privilegia o diálogo entre usuários e trabalhadores, fortalecendo-os para incorporar e legitimar a educação em saúde como instrumento da ESF.

O material de apoio disponibilizado ao grupo para auxiliá-lo nas discussões possibilitou aos participantes o contato com vários conceitos e práticas educativas. Assim, os integrantes das equipes conseguiram identificar suas dificuldades, relacionando-as com a falta de preparo acadêmico, de tempo e de espaço físico, com a relutância da população em aceitar inovações e com a não existência de uma educação permanente. Esses trabalhadores não se percebem como mediadores do processo educativo.

As reflexões nos permitiram vislumbrar um avanço importante em direção ao modelo preconizado pelo SUS. A ESF pode significar uma modificação institucional e não apenas uma mudança na relação entre trabalhadores de saúde e população (Oliveira, 2011). Há necessidade de o trabalhador aderir às práticas reflexivas, dialogadas, que possam midiatizar o empoderamento.

Entendemos que concepções e práticas da educação em saúde sejam importantes para compreender o agir educativo e como ele é operacionalizado pela equipe de trabalhadores, no cotidiano das unidades de ESF, 
visando ao processo de mudança social e ao empoderamento das pessoas. Contudo, não basta propor estratégias se não se investir na formação de gestores e trabalhadores sob a lógica da integralidade das ações em saúde, tornando-os aptos para compreenderem a realidade da vida das comunidades, criarem vínculos e trabalharem em equipe. Não basta investir na ESF e correr o risco de perpetuar um modelo autoritário, medicalizado e opressor.

\section{Colaboradores}

Sílvia Regina Gomes de Oliveira realizou pesquisa bibliográfica, executou os procedimentos de coleta de dados por meio de oficinas, trabalhou na discussão e análise dos dados, na produção e organização do texto; Águeda Lenita Pereira Wendhausen orientou, acompanhou o desenvolvimento da pesquisa e colaborou na produção textual do artigo.

Resumen Este estudio cualitativo buscó conocer la concepción y vivencia de 27 trabajadores de la Estrategia Salud Familiar sobre educación en salud. El desarrollo de la problematización, como la concebía Paulo Freire, facilitó el trabajo grupal participativo. En este recorte se discutieron dos de las categorías: prácticas educativas y sus enigmas, y (re)significación de las prácticas educativas. Los temas planteados fueron codificados, decodificados y develados en forma crítica. Asimismo se expresaron las dificultades, posibilidades y expectativas de la acción educativa. Los resultados revelaron las dificultades de los sujetos en diferentes aspectos de la acción educativa en sus prácticas y cómo son fuertes los resquicios de una práctica bancaria, preventiva y medicalizada. La reflexión oriunda de allí los sensibilizó, lo que demostró potencial para el desarrollo de prácticas educativas transformadoras y la necesidad de una educación permanente, a fin de ampliar sus habilidades dialógicas.

Palabras clave Fomento de la salud; salud familiar; educación en salud. 


\section{Notas}

1 Universidade Federal de Mato Grosso, Cuiabá, Brasil.

Mestre em Saúde e Gestão do Trabalho pela Universidade do Vale do Itajaí.

<siregol@hotmail.com>

Correspondência: Rua Lauro Müller, 740, apartamento 204, CEP 88301-401, Itajaí, Santa Catarina, Brasil.

2 Universidade do Vale do Itajaí, Itajaí, Santa Catarina, Brasil.

Doutora em Enfermagem pela Universidade Federal de Santa Catarina.

<agueda@univali.br>

\section{Referências}

ALVIM, Neide A. T.; FERREIRA, Marcia. A. Perspectiva problematizadora da educação popular em saúde e a enfermagem. Texto e Contexto Enfermagem, Florianópolis, v. 16, n. 2, p. 315-319, abr./jun. 2007.

BRANDÃO, Carlos. R. O que é método Paulo Freire. 7. ed. São Paulo: Brasiliense, 2005.

BRASIL. Ministério da Saúde. Portaria GM/MS n. 1.996 , de 20 de agosto de 2007. Dispõe sobre as diretrizes para a implementação da Política Nacional de Educação Permanente em Saúde e dá outras providências. Brasília, DF, ago.2007. Disponível em: <http://portal. saude.gov.br/portal/arquivos/pdf/Portaria_ 1996-de_20_de_agosto-de-2007.pdf $>$. Acesso em: 29 dez. 2012.

Ministério da Saúde. Secretaria de Gestão do Trabalho e da Educação na Saúde. Departamento de Gestão da Educação na Saúde. Política de educação e desenvolvimento para o SUS: caminhos para a educação permanente em Saúde. Brasília: Ministério da Saúde, 2004.
BRICEÑO-LEÓN, Roberto. Siete tesis sobre la educación sanitária para la participación comunitária. Cadernos de Saúde Pública, Rio de Janeiro, v. 12, n. 1, p. 7-30, jan./mar., 1996.

CECCIM, Ricardo Burg. Pacientes impacientes: Paulo Freire. In: BRASIL. Ministério da Saúde. Secretaria de Gestão Estratégica e Participativa. Departamento de Apoio à Gestão Participativa. Caderno de educação popular e saúde. Brasília: Ministério da Saúde, 2007. p. 32-45. (Série B. Textos Básicos de Saúde).

CHIESA, Anna M.; BERTOLOZZI, Maria R.; FONSECA, Rosa M. G. S. da. A enfermagem no cenário atual: ainda há possibilidade de opção para responder às demandas da coletividade?. O Mundo da Saúde, São Paulo, v. 24, n. 1, p. 67-71, jan./fev. 2000.

CHIESA, Anna M.; VERÍSSIMO, Maria D. L. O. R. A educação em saúde na prática do PSF. In: BRASIL. Ministério da Saúde. Instituto para o desenvolvimento da Saúde. Manual de enfermagem. Brasília: Ministério 
da Saúde, 2001. p. 34-42. Disponível em: $<$ www.ids-saude.org.br/enfermagem $>$. Acesso em: 2 nov. 2012.

CUTOLO, Luiz R. A. O SUS e a formação de recursos humanos. Arquivos Catarinenses de Medicina, Florianópolis, n. 2, p. 49-59, 2003.

DIERKS, Margarita S.; PEKELMAN, Renata. Manual para equipes de saúde: o trabalho educativo nos grupos. In: BRASIL. Ministério da Saúde. Secretaria de Gestão Estratégica e Participativa. Departamento de Apoio à Gestão Participativa. Caderno de educação popular e saúde. Brasília: Ministério da Saúde, 2007. p. 75-86. (Série B. Textos Básicos de Saúde).

FREIRE, Paulo. Pedagogia da autonomia: saberes necessários a prática educativa. 31. ed. Rio de Janeiro: Paz e Terra, 2005.

Pedagogia do oprimido. 49. ed. Rio de Janeiro: Paz e Terra, 2007.

KLEBA, Maria E. Participação social e saúde da família no contexto do Sistema Único de Saúde: apontamentos para o debate. In: ENCONTRO DE PESQUISA EM SAÚDE, 2., 2004, Anais... Itajaí: Univali, 2004. p.15-17.

LEONELLO Valéria M.; OLIVEIRA, Maria A.C. Construindo o diálogo entre saberes para ressignificar a ação educativa em saúde. Acta Paulista de Enfermagem, São Paulo, v. 22, n. esp. 70 anos, p. 916-920, 2009.

LUDKE, Menga; ANDRÉ, Marli E. D. A. Pesquisa em educação: abordagem qualitativa. São Paulo: Pedagógica e Universitária, 1986.
MIRANDA, Karla C. L.; BARROSO, Maria G. T. A contribuição de Paulo Freire à prática da educação crítica em enfermagem. Revista Latino-Americana de Enfermagem, Ribeirão Preto, v.12, n. 4, jul./ago.2004.

OLIVEIRA, Sílvia R.G. Educação em saúde e a estratégia saúde da família: o desafio do trabalhador em (re)significar a prática. 2011. 150f. Dissertação (Mestrado em Saúde e Gestão do Trabalho) - Universidade do Vale do Itajaí, Programa de Pós-Graduação em Enfermagem, Itajaí, 2011.

ROSCHKE, Maria A. Política nacional de educação permanente em saúde. (2008?). Disponível em: <www.escoladesaude.pr.gov. br/arquivos/File/mostra/EPS/Maria_Alice_ Roskche.pdf>. Acesso em: 29 dez. 2012.

SANTANA, José P.; CAMPOS, Francisco E.; SENA, Roseni R. de. Formação profissional em saúde: desafios para universidade. Brasília: Opas/OMS do Brasil, 2004.

TESSER, Charles D. Medicalização social (I): o excessivo sucesso do epistemicídio moderno na saúde. Interface: Comunicação, Saúde e Educação, Botucatu, v. 10, n. 19, p. 61-76, jan./jun. 2006.

VASCONCELOS, Eduardo M. Educação popular e a atenção à saúde da família. 3. ed. São Paulo: HUCITEC, 2006.

WENDHAUSEN, Agueda. O duplo sentido do controle social. Santa Catarina: Univali, 2002.

WENDHAUSEN, Agueda; SAUPE, Rosita. Concepções de educação em saúde e a estratégia de saúde da família. Texto Contexto de Enfermagem, Florianópolis, v. 12, n. 1, p. 17-25, jan./mar. 2003.

Recebido em 13/07/2012

Aprovado em 27/09/2012 